\title{
Article \\ Enhancing Dissolution Rate and Antibacterial Efficiency of Azithromycin through Drug-Drug Cocrystals with Paracetamol
}

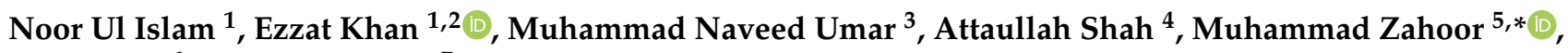 \\ Riaz Ullah ${ }^{6}$ and Ahmed Bari ${ }^{7}$
}

check for updates

Citation: Ul Islam, N.; Khan, E.; Naveed Umar, M.; Shah, A.; Zahoor, M.; Ullah, R.; Bari, A. Enhancing Dissolution Rate and Antibacterial Efficiency of Azithromycin through Drug-Drug Cocrystals with Paracetamol. Antibiotics 2021, 10, 939. https://doi.org/10.3390/ antibiotics10080939

Academic Editors: Andrew David Berti and Abdelwahab Omri

Received: 4 May 2021

Accepted: 9 July 2021

Published: 4 August 2021

Publisher's Note: MDPI stays neutral with regard to jurisdictional claims in published maps and institutional affiliations.

Copyright: (c) 2021 by the authors. Licensee MDPI, Basel, Switzerland. This article is an open access article distributed under the terms and conditions of the Creative Commons Attribution (CC BY) license (https:/ / creativecommons.org/licenses/by/ $4.0 /)$.
1 Department of Chemistry, University of Malakand, Chakdara 18800, Pakistan; nooruomchem@gmail.com (N.U.I.); ekhan@uom.edu.pk (E.K.)

2 Department of Chemistry, College of Science, University of Bahrain, Sakhir 32038, Bahrain

3 Jacobs University School of Life Sciences and Chemistry, Campus Ring 1, 28759 Bremen, Germany; m.naveedumar@uom.edu.pk

4 Pakistan Institute of Engineering and Applied Sciences, National Institute of Lasers and Optronics College (NILOP-C, PIEAS), Islamabad 44000, Pakistan; attashah168@gmail.com

5 Department of Biochemistry, University of Malakand, Chakdara 18800, Pakistan

6 Department of Pharmacognosy, College of Pharmacy, King Saud University, Riyadh 11451, Saudi Arabia; rullah@ksu.edu.sa

7 Department of Pharmaceutical Chemistry, College of Pharmacy, King Saud University, Riyadh 11451, Saudi Arabia; abari@ksu.edu.sa

* Correspondence: mohammadzahoorus@yahoo.com

\begin{abstract}
Cocrystallization is a promising approach to alter physicochemical properties of active pharmaceutical ingredients (hereafter abbreviated as APIs) bearing poor profile. Nowadays pharmaceutical industries are focused on preparing drug-drug cocrystals of APIs that are often prescribed in combination therapies by physicians. Physicians normally prescribe antibiotic with an analgesic/antipyretic drug to combat several ailments in a better and more efficient way. In this work, azithromycin (AZT) and paracetamol (PCM) cocrystals were prepared in 1:1 molar ratio using slow solvent evaporation method. The cocrystals were characterized by Fourier transform infrared (FTIR), Raman spectroscopy, powder X-ray diffraction (PXRD), differential scanning calorimeter (DSC), thermo gravimetric analysis (TGA) and high-performance liquid chromatography (HPLC). Vibrational spectroscopy and DSC confirmed that both APIs interact physically and showed chemical compatibility, while PXRD pattern of the starting material and products revealed that cocrystal have in a unique crystalline phase. The degree of hydration was confirmed by TGA analysis and result indicates monohydrate cocrystal formation. The HPLC analysis confirmed equimolar ratio of AZT:PCM in the cocrystal. The in vitro dissolution rate, saturation solubility, and antimicrobial activity were evaluated for AZT dihydrate and the resulting cocrystals. The cocrystals exhibited better dissolution rate, solubility and enhanced biological activities.
\end{abstract}

Keywords: antibacterial agents; azithromycin; cocrystallization; dissolution studies; paracetamol

\section{Introduction}

Recently, researchers have focused on preparation of drug-drug cocrystals (DDCs) for commercial purposes. This approach is more practical as physician describes combination of different drugs to get far reaching results and if such combination is converted into cocrystals it will not only reduce the compliance of the patients but will be economic as well. Currently, limited literature is available to describe DDCs. The DDC of meloxicam and aspirin cocrystal has been developed with a better bioavailability and therapeutic concentration in blood plasma as compared to meloxicam [1]. Better dissolution [2] and several other physical properties have been improved for some drugs with some limitations [3]. The techniques of cocrystallization have been very successful in HIV related drugs [4], 
combination drugs [5], tuberculosis [6], effective antibacterial drugs [7]. Patient compliance, solubility, dissolution rate, bioavailability, and stability of at least one component are improved through DDCs [8]. Though DDCs syntheses are a viable strategy to modulate properties of a drug to resolve the associated problems with conventional combination drugs therapy [9]. However, it may have a dose proportionality issue in designing such type of cocrystals. As the molar ratio of drugs is fixed, cocrystal formation occurs according to the stoichiometric rule, although the dose of each drug varies depending on the patient's age, race or ethnicity and clinical indications [8].

Azithromycin (AZT, shown in Figure 1) is a semisynthetic macrolide derivative of erythromycin A found as monohydrate $(\mathrm{MH})$, dihydrate $(\mathrm{DH})$, semi-hydrate solvates [10-12] and pseudopolymorphic forms [13]. However, the $\mathrm{MH}$ and $\mathrm{DH}$ crystalline forms are more stable compared to other forms $[13,14]$. The $\mathrm{MH}$ form is used less due hygroscopic properties while the DH form is preferably used for therapeutic applications [13]. AZT in biopharmaceutical classification system (BCS) is class-II (low solubility/high permeability) API [15]. It is used in the treatment of several pediatric and adult infections [16-18], such as lower and upper respiratory tract infection, bronchitis, laryngitis, pneumonia and middle ear infections [19]. Additionally, it is also an effective therapeutic antibiotic used in the treatment of other diseases like tonsillitis, sexually transmitted diseases and skin infections [20]. When the drug is administered orally, its solubility in physiological fluid is very poor, which accounts for low bioavailability [21]. The drug, AZT, absorbs quickly, exhibiting excellent bioavailability once its solubility problem is resolved. Therefore, to achieve good pharmacological results, the solubility of the drug must be enhanced for improved absorption and bioavailability [15]. Furthermore, the drug exhibits bitter taste [22] and has been found to be degraded photocatalytically [23]. A number of approaches like nanoparticles [24,25], nanosuspension [26], microemulsion [27], solid dispersion [21,28], co-spray dried composite powder formulation [29] and metal complexes [30] have been used to enhance its physicochemical properties of solubility and dissolution. The bitterness of AZT was masked by preparing microparticles [31] and nanoparticles without affecting dissolution rate [32].

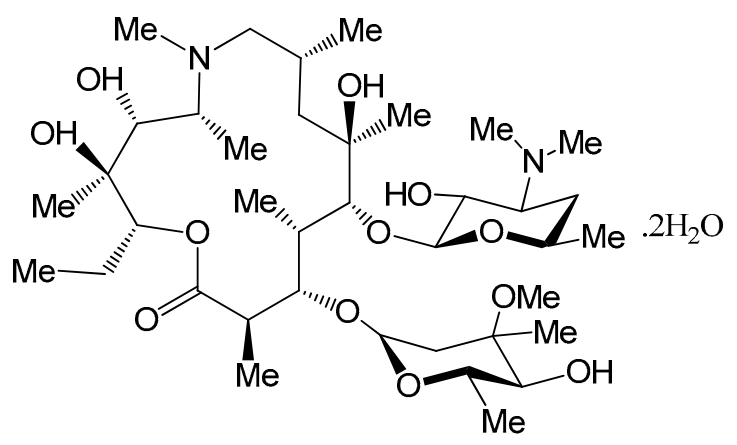<smiles>CC(=O)Nc1ccc(O)cc1</smiles>

Azithromycin dihydrate

Figure 1. Chemical structures of azithromycin dihydrate (AZT DH) and paracetamol (PCM).

Paracetamol (PCM, shown in Figure 1) exists in three polymorphic forms; a stable phase (I) and two metastable phases (II,III). Form I packs a herringbone motif, while forms II and III display layered structures [33,34]. It is used as an analgesic/antipyretic drug [35] and based on BCS it is classified class-III (low permeability, high solubility) API [36]. The crystal structure of PCM reveals hydrogen bonding, i.e., the crystal consists of potential Hbonding sites. Solid dosage forms of PCM may contain single-ingredient or in combination with other non-steroidal anti-inflammatory drugs (NSAIDs), opioids and antispasmodic drugs [37]. Although PCM contains no apparent basic or acidic sites, the existence of $\mathrm{H}$ bond acceptor (oxygen in amide) and donor ( $\mathrm{OH}$ and $\mathrm{NH}$ groups) makes them an excellent model drug for cocrystallization [38]. The cocrystallization of PCM has been extensively examined and several cocrystals have been successfully developed with coformers N,N- 
dimethyl-piperazine, piperazine, morpholine, 1,4-dioxane, 2,4-pyridinedicarboxylic acid and 4,4'-bipyridine [36].

A physician normally describes an antibiotic with an analgesic/antipyretic drug and the usual practice of simultaneous oral administration. Therefore, in the current study, an attempt has been made to synthesize cocrystal (AZT-PCM) system by solvent evaporation method. The possible intermolecular interactions and chemical compatibility of APIs was studied by Fourier transform infrared (FTIR), Raman spectroscopy and differential scanning calorimeter (DSC) techniques. New crystalline phase and thermal stability of the product were confirmed by powder X-ray diffraction (PXRD) and thermo gravimetric analysis (TGA), respectively. The molar ratio of components in the final product was confirmed by high-performance liquid chromatography (HPLC). Dissolution rate and antibacterial activity of cocrystals were studied and results were compared with raw azithromycin dihydrate (AZT DH) to evaluate its pharmaceutical applicability. The overall scheme of the study is given in Figure 2.
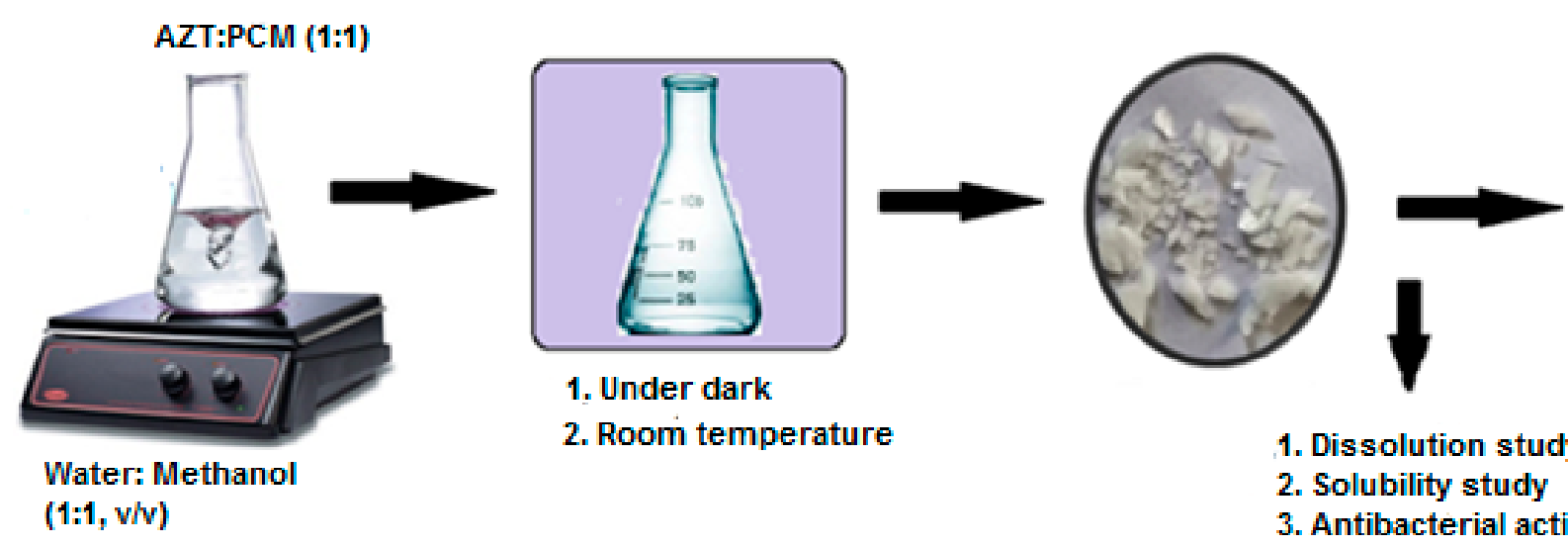

1. FTIR

2. Raman

3. PXRD

4. DSC

5. TGA

6. HPLC

\section{Room temperature}

\section{Dissolution study \\ 2. Solubility study \\ 3. Antibacterial activity}

Figure 2. Scheme of study for synthesis, characterization and in vitro evaluation of cocrystal.

\section{Results and Discussion}

\subsection{Vibrational Spectroscopic Characterization}

Cocrystal formation is the result of non-covalent interactions between different molecular components [39-45]. The existence of single component in the resulting bulk without structural variation is the key feature of the technique. It is therefore always observed that the vibrational (FTIR and Raman) spectroscopy is an excellent technique to characterize and study cocrystals.

\subsubsection{FTIR Spectroscopy}

The FTIR analysis has been a valuable and extensively used tool for characterization and identification of new solid forms, in addition to other spectroscopic techniques [46]. The FTIR spectra (Figure 3) of raw drugs, physical mixture and cocrystal were obtained for possible interaction and chemical compatibility. The characteristic peaks pertaining to raw AZT DH can be assigned based on previously reported data $[21,26,28]$. The characteristic peaks observed at 3556 and $3486 \mathrm{~cm}^{-1}$ are assigned to OH-group, typically broad due to extensive intermolecular $\mathrm{H}$-bonding, bands in the range $2750-3020 \mathrm{~cm}^{-1}$ indicate the presence of $\mathrm{CH}$-aliphatic and $1718 \mathrm{~cm}^{-1}$ shows the presence of $\mathrm{C}=\mathrm{O}$ stretching frequency. Signals at $1458\left(\mathrm{CH}_{3}-\mathrm{O}\right), 1373\left(\mathrm{CH}_{2}-\mathrm{O}\right), 1165$ (C-O-C asymmetric stretch) and $1050 \mathrm{~cm}^{-1}$ (C-O-C symmetric stretch) are within the expected range. The characteristic peaks of PCM are observed at $3319(\mathrm{OH}), 3258(\mathrm{NH}), 3160-3032\left(\mathrm{CH}_{3}\right), 1654(\mathrm{C}=\mathrm{O}), 1610(\mathrm{C}=\mathrm{C}), 1557(\mathrm{NH}$ bending), 1507 (CH asymmetric), 1443-1437 (C-C), 1368-1328 and 1260-1227 (symmetrical bending in $\mathrm{CH}$ and $\mathrm{CN}$ aryl stretching), 1171 and $965 \mathrm{~cm}^{-1}$ (C-O and $\mathrm{C}-\mathrm{N}$ ) which show agreement with the reported data $[47,48]$. 


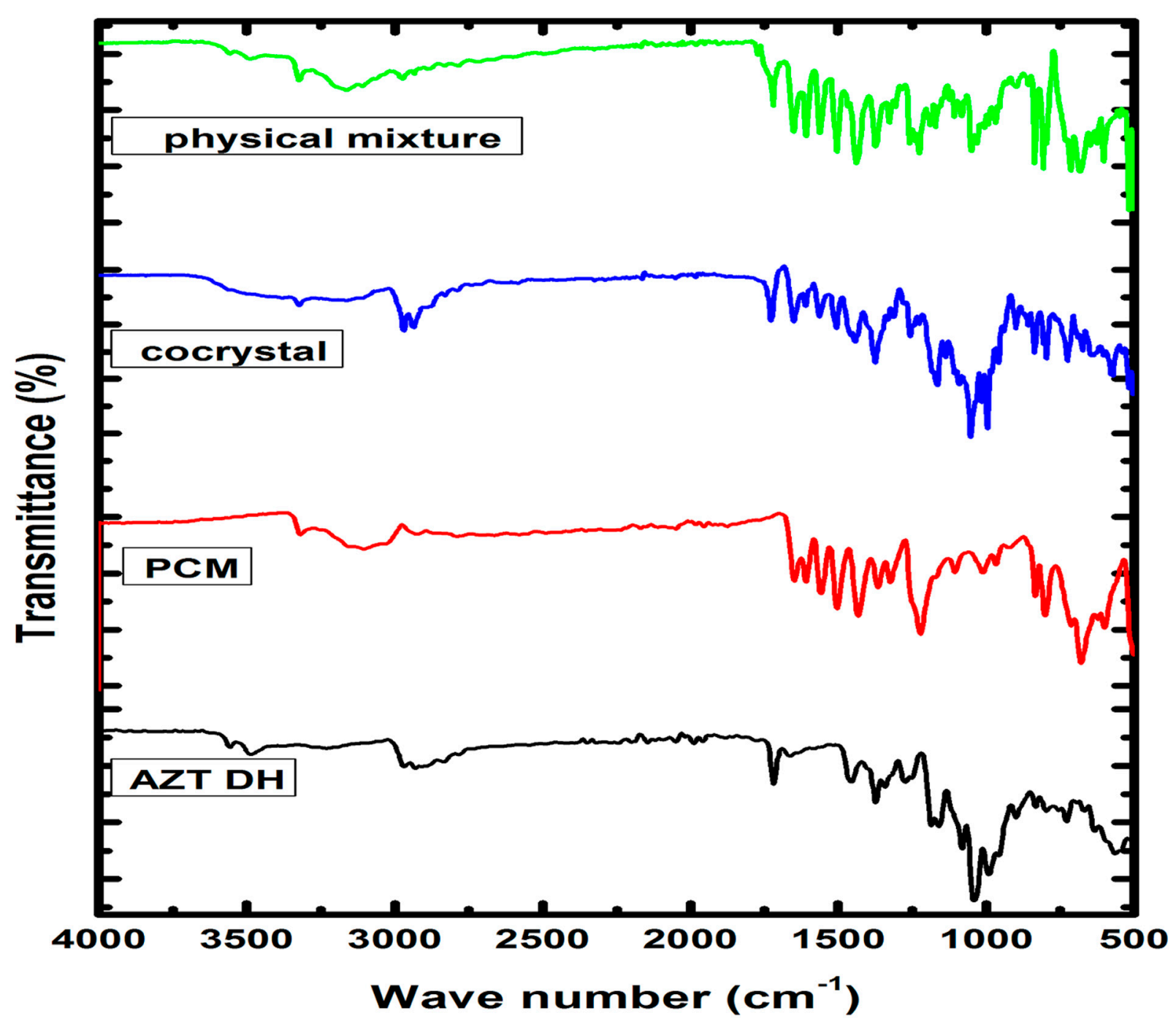

Figure 3. FTIR spectra of AZT DH, PCM, cocrystal and physical mixture.

Due to the complex FTIR spectrum of cocrystal (AZT-PCM) the unambiguous assignment of peaks is very tough task. However, attenuation, broadening and slight change in position of peaks can give a hint for Van der Waals interactions [49,50]. An abnormally broad peak formed in the region of $3600-3015 \mathrm{~cm}^{-1}$ indicates some new set of H-bond interactions [51,52], while no such peak formation is observed in the physical mixture spectrum. The $\mathrm{OH}$ of $\mathrm{PCM}$ is involved in intermolecular hydrogen bonding with $\mathrm{N}$ in pure solid state while in cocrystal the $\mathrm{OH}$ stretching peak $\left(3319 \mathrm{~cm}^{-1}\right)$ and $\mathrm{NH}$ bending peak $\left(1557 \mathrm{~cm}^{-1}\right)$ of PCM have shifted to 3327 and $1565 \mathrm{~cm}^{-1}$, respectively. The peak of AZT DH shifted from 1718 to $1727 \mathrm{~cm}^{-1}$ may be due to the involvement of $\mathrm{C}=\mathrm{O}$ functional group in H-bonding, where slight shift of electrons density and deduction of bond order can be observed. From 1718-1458 $\mathrm{cm}^{-1}$, the AZT DH remains inactive [53] where several characteristic peaks that correspond to PCM appeared in this region [36]. An overall inspection of spectrum indicates the existence of PCM and shifting of $\mathrm{OH}$ and $\mathrm{NH}$ peaks revealed the establishment of hydrogen bonding with AZT. Moreover, slight shifting in wave number values of peaks was also observed in the fingerprint region. From the above discussion it is strongly suggested that AZT and PCM interact through non-covalent interactions with each other to afford cocrystals. Furthermore, both drugs showed compatibility with each other because all characteristic peaks of both components appeared in the FTIR spectrum of the resulted cocrystal (Figure 3). 


\subsubsection{Raman Spectroscopy}

The establishment of intermolecular interactions between cocrystal components leads to valuable changes in the Raman spectra, as shown in Figure 4. The Raman spectrum of AZT DH exhibited bands at positions 2961, 2930, 2880 and $2824 \mathrm{~cm}^{-1}$, while PCM had peaks at 3088, 3053 and $2919 \mathrm{~cm}^{-1}$. The peaks 2921 and $2930 \mathrm{~cm}^{-1}$ of AZT DH and PCM appeared at $2930 \mathrm{~cm}^{-1}$ (broad peak) and the doublet at 2955 and $2970 \mathrm{~cm}^{-1}$ of AZT DH appeared as a single peak with enhanced intensity at $2961 \mathrm{~cm}^{-1}$ in the spectrum of the corresponding cocrystal. The peaks at 3088 and $3055 \mathrm{~cm}^{-1}$ correspond to PCM almost disappeared in cocrystal while peaks of AZT DH at 2824 and $2880 \mathrm{~cm}^{-1}$ remained unchanged.

AZT DH has a peak at $1692 \mathrm{~cm}^{-1}$ corresponding to the $\mathrm{C}=\mathrm{O}$ stretching, which shifted to a higher wave number $1712 \mathrm{~cm}^{-1}$ during cocrystallization. The same blue shift of carbonyl peak was also observed in the FTIR spectrum. The peak shifting indicates that the carbonyl group of AZT participates in hydrogen bonding. The amide $(\mathrm{C}=\mathrm{O})$ stretch and other characteristics peaks 1632, 1600, $1547 \mathrm{~cm}^{-1}$ of PCM appeared weak and broad at $1664,1621,1550 \mathrm{~cm}^{-1}$ in a cocrystal complex. Apart from these changes, several peaks of AZT DH and PCM in the stretching and bending vibration regions were shifted (frequency and intensity) in cocrystal spectrum, depending upon their participation in secondary interactions.

The obtained Raman spectral results are in strong agreement with previously published data for cocrystals $[54,55]$. Raman experimental results indicated that the crystalline phase of the cocrystal is not a simple combination of starting materials, but a different crystal phase due to hydrogen bonding interactions between AZT and PCM. Therefore, from Raman analysis it is further confirmed that AZT-PCM afford cocrystals as a result of non-covalent interactions.

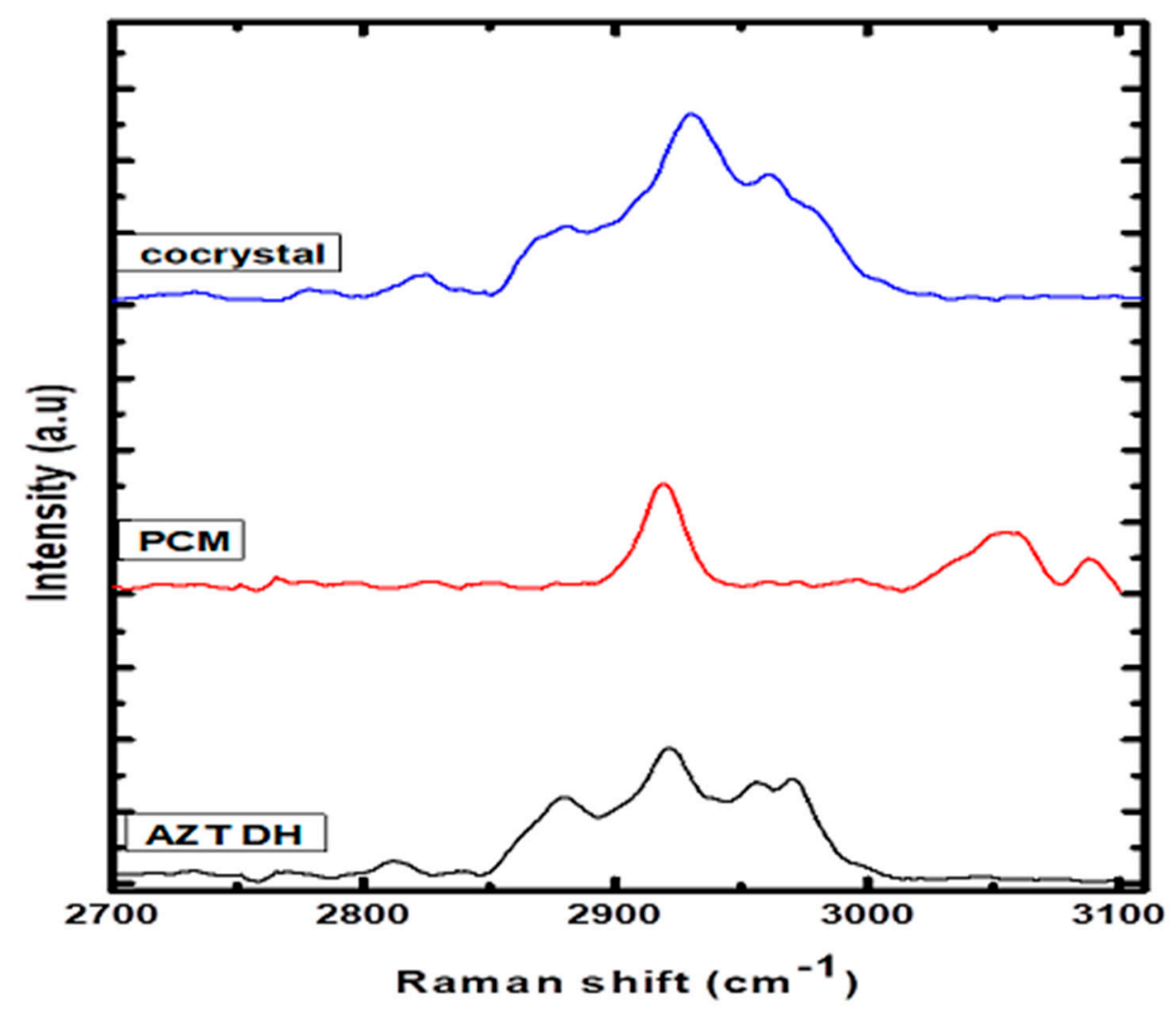

(a)

Figure 4. Cont. 


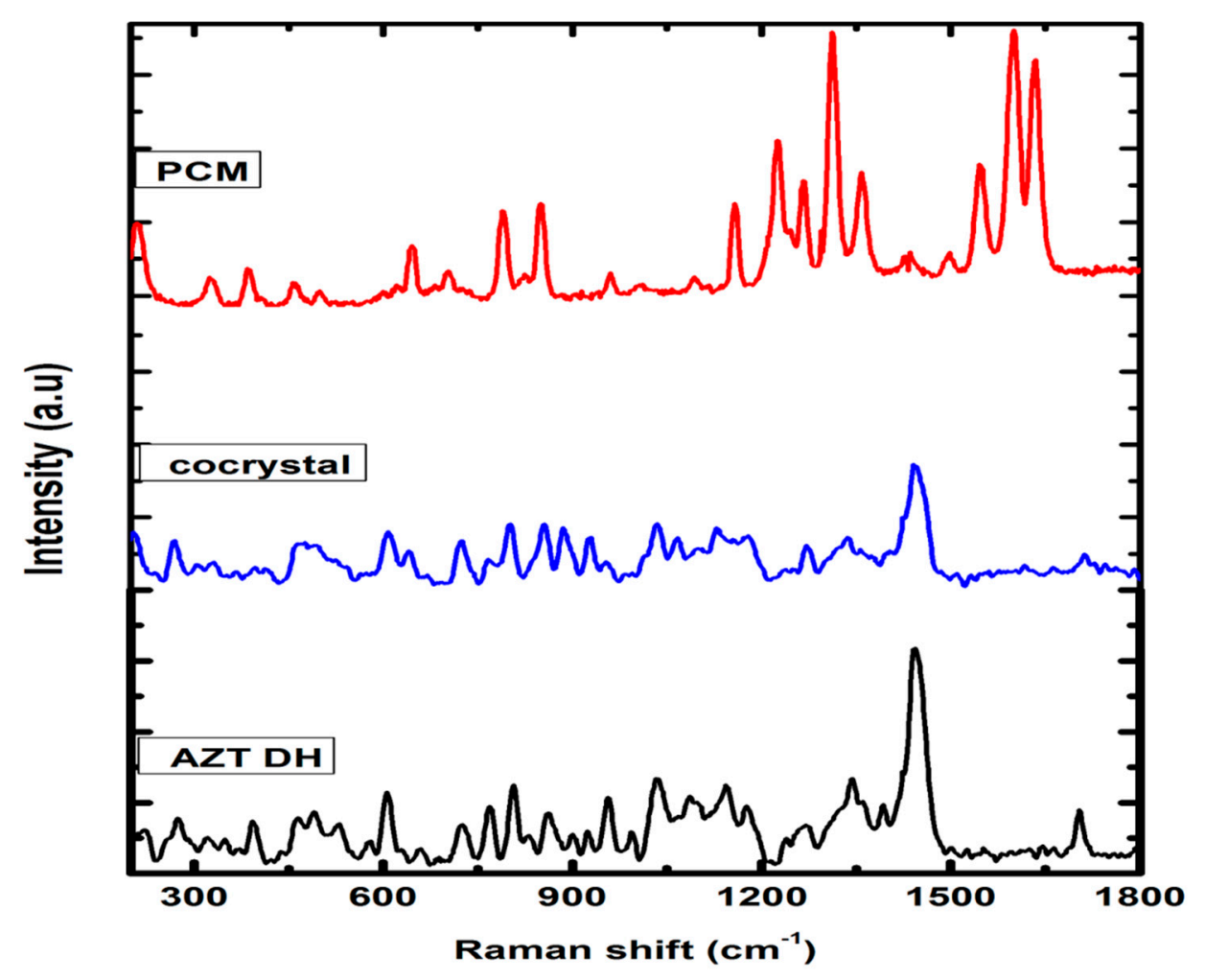

(b)

Figure 4. (a) Raman spectra of AZT DH, PCM and cocrystal range (2700-3100 cm $\mathrm{cm}^{-1}$ ). (b) Raman spectra of PCM, AZT DH and the cocrystal range $\left(500-1750 \mathrm{~cm}^{-1}\right)$.

\subsection{PXRD Characterization}

For detailed structural information, crystals with appropriate dimensions and size have to be prepared, which is often a hectic task and fails in many instances. Another limitation of single crystal analysis is that the selected crystal may represent a side product, not the desired polycrystalline product (bulk). Moreover, single crystal analysis is time consuming and not a readily available technique. Conversely, PXRD is a readily available technique generally used for confirmation and determination of bulk purity and crystallinity of the bulk material [56]. The DH form of AZT was re-crystalized from the same solvent system used in the preparation of cocrystals and subjected to PXRD analysis along PCM and cocrystals. Although the authentic data about cocrystals can be obtained from single crystal XRD diffractogram, in some cases where the crystal obtained is not suitable for single crystal XRD analysis, PXRD analysis is preferred to get the data about the crystals formed [57]. Referring to the study of Wu et al. [57], PXRD analysis has been used in this study to confirm the crystallinity of the product formed. Before the PXRD measurement, we crushed the single crystals formed to eliminate the effects of preferential orientation and enhance the clarity of the small diffraction peaks [57]. New solid phases were identified as changes were observed in the PXRD pattern, by comparing the starting material and final product [58]. The PXRD diffractograms of the prepared cocrystal and raw materials are given in Figure 5. The diffractograms of pure AZT and recrystallized AZT exhibited DH and $\mathrm{MH}$ forms, respectively which showed good agreement with previously reported experimental PXRD patterns [57]. The diffraction pattern of the cocrystal exhibited different pattern to that of starting materials and recrystallized AZT MH. The different PXRD patterns of cocrystals in comparison with the starting precursors indicate that the new crystalline phase material has been successfully formed with a different crystalline phase $[57,59]$. 


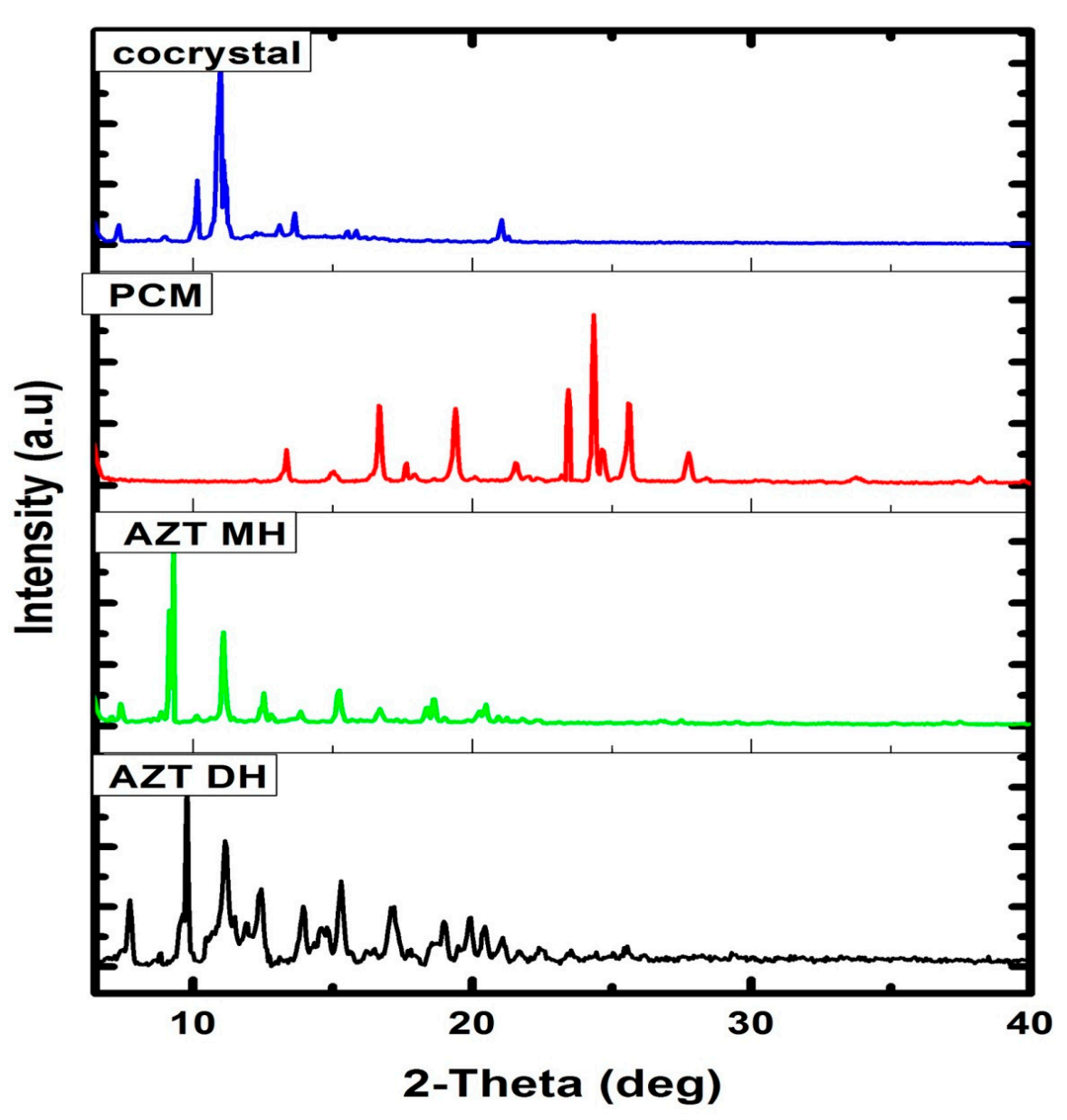

Figure 5. PXRD patterns of AZT DH, AZT MH, PCM and cocrystal.

\subsection{Thermal Analysis}

\subsubsection{DSC Analysis}

DSC analyses are extensively utilized for cocrystals confirmation. The thermal behavior of newly prepared cocrystals and corresponding raw materials were investigated using DSC (Figure 6). The endothermic peak of AZT DH and PCM were observed at $126.7^{\circ} \mathrm{C}$ and $168.23^{\circ} \mathrm{C}$, respectively. Meanwhile, the endothermic peak at $143.27^{\circ} \mathrm{C}$ along with shoulder peak provide enough insight regarding the formation of cocrystal [60]. Moreover, the shifting of endothermic peaks of AZT-PCM physical mixture $(1: 1, w / w)$ to lower temperature previously reported, which indicating strong interactions between APIs [61]. The survey of 50 samples was evaluated, the results showed $51 \%$ cocrystals melting point in between those of respective APIs and their coformer, while 39\% were lower than both of the components, only for $4 \%$ the value was similar to either the API or conformer, and $6 \%$ had higher melting than the parent material. From the results it has been concluded that melting point of an API can shift due to the formation of cocrystals [62]. During the course of our study, the melting peak of the cocrystal was observed in between both components. Therefore, DSC analysis reveals the formation of new cocrystal material [63,64]. Furthermore, a different position of the melting peak also suggested physical interactions developed between both the APIs in their resulted cocrystal [61]. The binary phase diagram is also given in Figure $\mathrm{S} 1$ shows the physical interaction between corresponding constituents. Additionally, the preliminary melting points were determined through melting point analyzer are given in Table S1. 


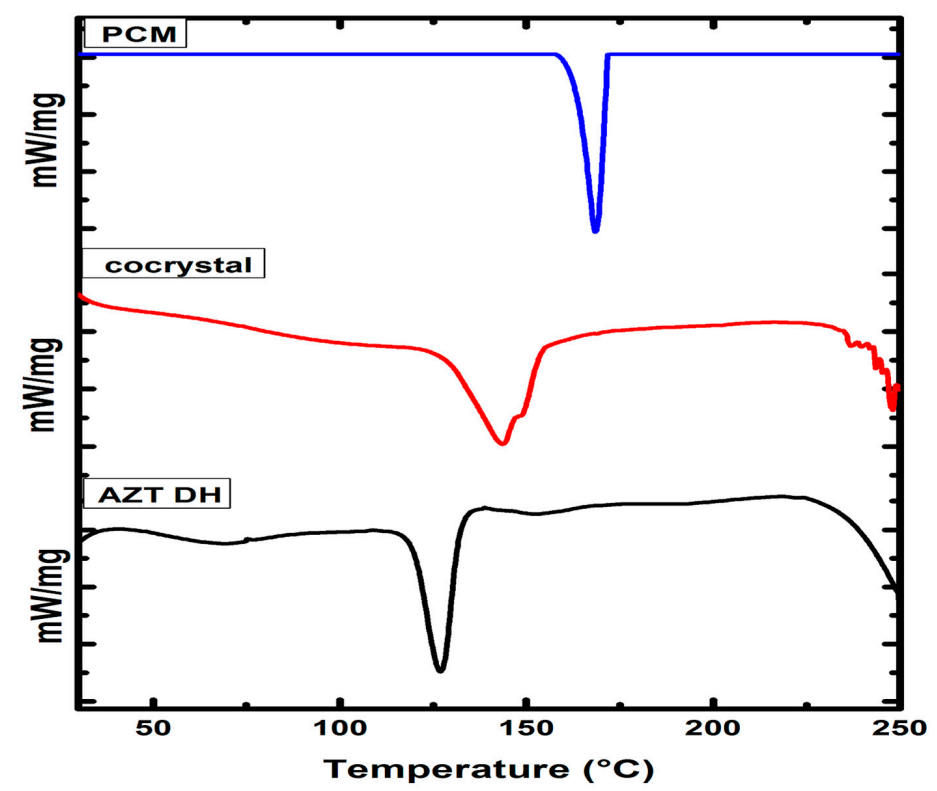

Figure 6. The DSC thermograms AZT DH, PCM and cocrystal.

\subsubsection{Thermogravimetric Analysis (TGA)}

The degree of hydration and thermal stability of cocrystal was evaluated by TGA. The obtained thermograms of the cocrystal and respective pure drugs are presented in Figure 7 . The thermogram of the cocrystal exhibiting the transition of the cocrystal from a hydrated to anhydrous form. The observed weight loss (2.90\%) up to onset temperature corresponds to the loss of water and other solvent residue molecules, as theoretically $1.96 \%$ and $3.84 \%$ water molecule weight loss is encountered while preparing AZT-PCM (1:1) $\mathrm{MH}$ and DH cocrystals, respectively. In case of semihydrate solvated form (AZT-PCM. $\mathrm{H}_{2} \mathrm{O} . \frac{1}{2} \mathrm{CH}_{3} \mathrm{OH}$ ) [12], where methanol is also attached, the mass loss is theoretically $3.64 \%$. The $2.90 \%$ mass loss up to onset temperature can be explained by the fact that when water/methanol mixture is used in formulation, the $\mathrm{DH}$ form of AZT is converted into $\mathrm{MH}$ form. MH form of AZT was previously obtained in a water/ethanol mixture [13] which is hygroscopic as mentioned earlier and the loss $2.90 \%$ may be due to some unbound water molecules along with bounded water molecules associated with $\mathrm{MH}$ form.

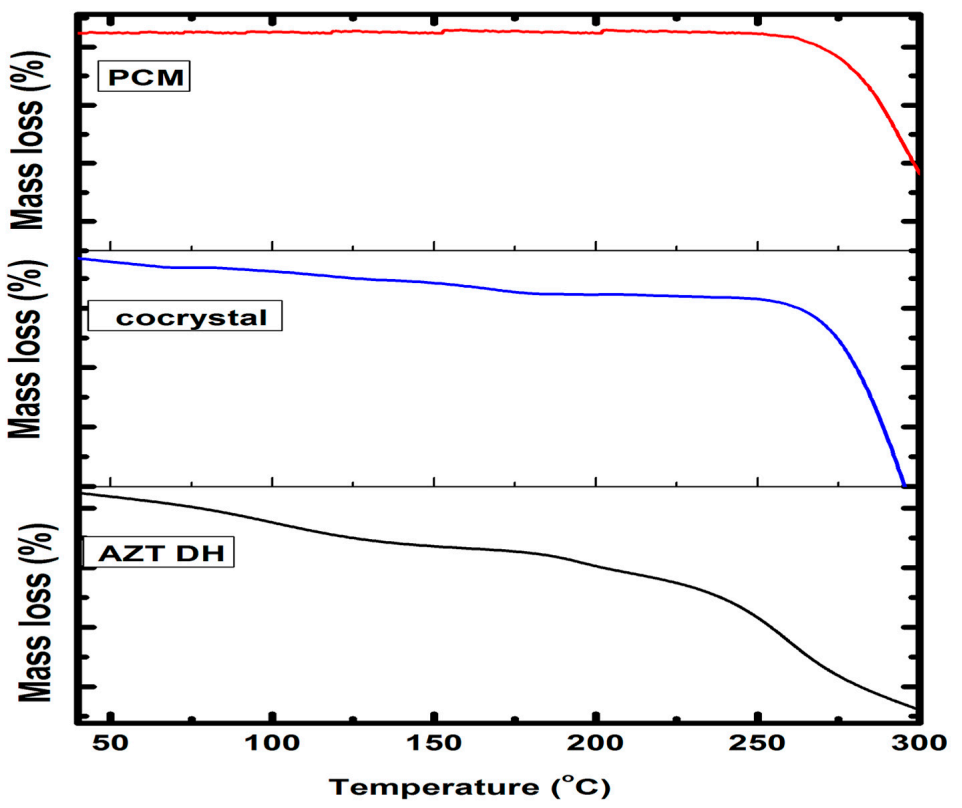

Figure 7. TGA thermograms of AZT DH, PCM and cocrystal. 
Previously compiled data revealed that AZT DH transformed to MH, followed by anhydrous form up to its melting temperature [65]. Similarly, the weight loss of cocrystal up to onset temperature attributed to the removal of unbound or bound (solvate) molecules from cocrystals [57]. Temperature above the melting point causes the degradation of cocrystals [66]. Therefore, the weight loss of AZT-PCM cocrystals before onset temperature may be due to the loss of water molecules from cocrystals or residual solvent elimination or water absorbed by the samples, while weight loss starting from $240^{\circ} \mathrm{C}$ is due to degradation. Little weight loss was also observed after melting temperature and before degradation, which may be due the volatilization of components of the cocrystal.

\subsection{HPLC Analysis}

Molar ratio of olanzapine and carbamazepine in their nicotinamide cocrystals were determined by HPLC analysis [67]. Therefore, the molar ratio of AZT was determined in cocrystals using previously developed and validated HPLC method [68]. The AZT concentration in cocrystals was $81 \%$, while theoretical concentration in case of cocrystal (combined in 1:1 ratio) is about $83 \%$. Experimental and theoretical values are in good agreement therefore, it is suggested that cocrystals have successfully formed where both the synthons are present in equimolar ratios.

\subsection{Powder Dissolution Study}

The in vitro drug release studies of AZT DH and the prepared cocrystal were performed in phosphate buffer ( $\mathrm{pH}$ 6.8), acetate buffer $(\mathrm{pH} 4.5)$ and $0.1 \mathrm{mM} \mathrm{HCl}$. The result displayed in Figure 8 reveals that cocrystal exhibited a better dissolution rate than pure AZT DH. Due to agglomeration and poor wettability, pure AZT DH showed poor dissolution up to one hour [21]. However, the better dissolution performance of the resulting cocrystal can be traced to changes in size, shape, crystalline pattern [57] and hydrophilic nature of PCM [36].

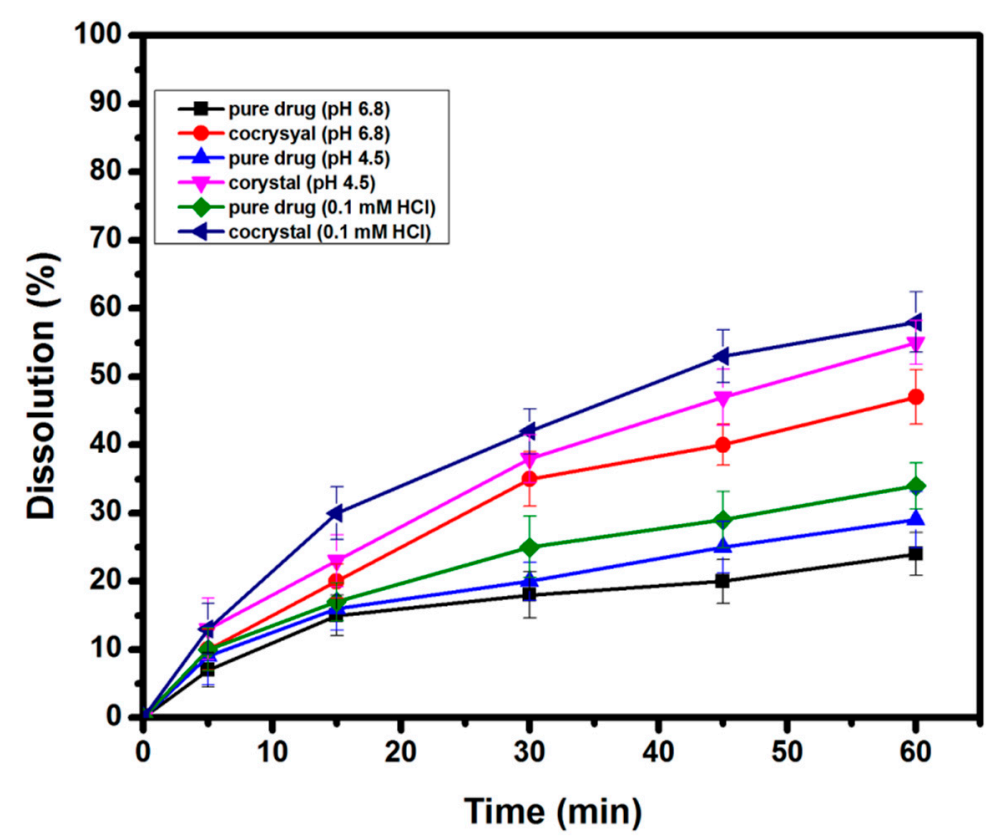

Figure 8. Powder dissolution rate of AZT DH and cocrystal in different dissolution medium.

\subsection{Saturation Solubility Studies}

The solubility of AZT DH in aqueous and phosphate buffer solution (pH 6.8) was calculated for pure drug and a cocrystal. The obtained results presented in Table 1 indicate that the solubility of AZT has significantly improved through cocrystallization. 
Table 1. Saturation solubility of AZT DH and cocrystal.

\begin{tabular}{ccc}
\hline Solubility Medium & Pure Drug $(\mu \mathrm{g} / \mathrm{mL})$ & Cocrystal $(\mu \mathrm{g} / \mathrm{mL})$ \\
\hline Distilled water & $55 \pm 1.31$ & $7 \pm 1.42^{* * *}$ \\
Phosphate Buffer $(\mathrm{pH} 6.8)$ & $60 \pm 1.28$ & $80 \pm 1.40^{* * *}$ \\
* $_{* * *}$ indicates significant difference $(p<0.05)$ & when t-test is applied for comparing the solubility values of cocrystal \\
with that of a pure drug.
\end{tabular}
with that of a pure drug.

\subsection{Antibacterial Studies}

The comparative zone of inhibition and MIC studies of the selected antibiotic and cocrystal were performed against Escherichia coli (E. coli), Salmonella typhi (S. typhi) and Klebsiella pneumonia (K. pneumonia) bacterial strains [43], the results obtained have been summarized in Tables 2 and 3, respectively. Cocrystals exhibited better results than the parental drug even though a smaller amount of AZT exists in the cocrystal. It may be due to a faster dissolution rate [69] or due to AZT-PCM cocrystal physicochemical interactions [7] or increasing diffusion through the bacterial cell [70]. Moreover, PCM also exhibited mild antimicrobial effectiveness, which may contribute towards enhanced efficiency of antibacterial activity of cocrystals [71]. The activity of the cocrystal in terms of bacterial inhibition was improved; the technique is promising and can be modified for MDRS (multidrug resistant strains) in future studies.

Table 2. Antimicrobial activity of AZT DH and cocrystal against different bacterial strains.

\begin{tabular}{cccc}
\hline Bacterial Strain & Sample Amount $(\boldsymbol{\mu g})$ & $\begin{array}{c}\text { AZT DH } \mathbf{( 1 0 0 \% ) ~ Z o n e ~ o f ~ I n h i b i t i o n ~} \\
(\mathbf{m m})\end{array}$ & $\begin{array}{c}\text { Cocrystal (83\%) Zone of Inhibition } \\
(\mathbf{m m})\end{array}$ \\
\hline & 5 & $21 \pm 0.45$ & $23 \pm 0.41^{* *}$ \\
K. pneumonia & 2.5 & $17 \pm 0.40$ & $18 \pm 0.37^{*}$ \\
& 1.25 & $14 \pm 0.35$ & $15 \pm 0.30^{* *}$ \\
& 0.62 & $10 \pm 0.25$ & $12 \pm 0.23^{* * *}$ \\
E. coli & 5 & $15 \pm 0.32$ & $16 \pm 0.27^{*}$ \\
& 2.5 & $10 \pm 0.30$ & $9 \pm 0.25^{* * *}$ \\
S. typhi & 1.25 & $8 \pm 0.25$ & - \\
& 0.62 & $13 \pm 0.35$ & $13 \pm 0.31^{*}$ \\
& 5 & $9 \pm 0.30$ & $10 \pm 0.27^{* *}$ \\
\end{tabular}

${ }^{* * *} p \leq 0.0005,{ }^{* *} p \leq 0.005$, while $* \leq 0.05$. Percent concentration of active antibiotic in the formulations presented in the brackets in the first row of columns two and three of the table.

Table 3. MIC values of pure AZT DH and cocrystal against different bacterial strains.

\begin{tabular}{cccc}
\hline \multirow{2}{*}{ Sample } & \multicolumn{3}{c}{ MIC $(\mu \mathrm{g} / \mathrm{mL})$} \\
\cline { 2 - 4 } & E. coli & S. typhi & K. pneumonia \\
\hline AZT DH $(100 \%)$ & 64 & 128 & 64 \\
Cocrystal $(83 \%)$ & 64 & 64 & 32 \\
\hline
\end{tabular}

In the brackets in the first column of the table are the percent concentrations of active antibiotic in the formulations.

\section{Experimental Section}

\subsection{Materials}

AZT DH $\left(\mathrm{C}_{38} \mathrm{H}_{72} \mathrm{~N}_{2} \mathrm{O}_{12} \cdot 2 \mathrm{H}_{2} \mathrm{O}, 98 \%\right)$ and PCM $\left(\mathrm{CH}_{3} \mathrm{CONHC}_{6} \mathrm{H}_{4} \mathrm{OH}, 98 \%\right)$ were obtained from the local pharmaceutical industry. Methanol (HPLC grade), $\mathrm{HCl}(37 \%)$ and $\mathrm{KH}_{2} \mathrm{PO}_{4}$ were purchased from Sigma Aldrich, while filtered, double distilled water was purchased from a local market. All chemicals were used without a purity test or further processing. 


\subsection{Synthesis of Cocrystals}

Solution of AZT DH and PCM in water/methanol $(1: 1, v / v)$ solvent system was prepared and sonicated for $10 \mathrm{~min}$ at $40{ }^{\circ} \mathrm{C}$; it was allowed to cool to room temperature in the dark. Crystalline materials obtained after a few days were separated from the solution and were dried under the vacuum at $40^{\circ} \mathrm{C}$. The prepared cocrystals were stored in the dark (as a precautionary measure) for further analysis.

\subsection{Preparation of Physical Mixture}

The physical mixture of AZT DH and PCM was prepared in equimolar amounts. Both drugs were transferred into micro tube and mixed thoroughly (for better homogeneity) for $15 \mathrm{~min}$ at $30 \mathrm{rpm}$ using vortex mixer. The sample was stored at ambient temperature till further studies.

\subsection{Vibrational Studies}

FTIR analyses were performed using FTIR spectrophotometer (PerkinElmer spectrum10.5.1). The FTIR spectra of AZT DH, PCM, cocrystals and physical mixture were recorded in the range of 4000-400 $\mathrm{cm}^{-1}$. Raman spectra were obtained using Lab RAM HR, Horiba Jobin Yvon, France. The spectra of pure drugs and cocrystals were recorded in the range of $100-3200 \mathrm{~cm}^{-1}$.

\subsection{Powder X-ray Diffraction (PXRD)}

The PXRD analysis for cocrystals and starting precursors were performed using JDX 3532 Jeol Japan X-Ray diffractometer. The samples were scanned at $2 \theta$ from $6-40^{\circ}$ with $0.05^{\circ}$ increments and counts were accumulated for $1 \mathrm{~s}$ per step.

\subsection{Thermal Analysis}

Thermal responses of cocrystals and respective drugs were measured by DSC-60 (Shimadzu, Japan) taking $4.6 \mathrm{mg}$ of the sample. Under constant nitrogen gas flow, the samples were heated at the rate of $10^{\circ} \mathrm{C} / \mathrm{min}$ in the range of 25 to $250{ }^{\circ} \mathrm{C}$. The STARe software was used for data processing and analysis.

Thermal gravimetric study was done with the help of Diamond Series TG/DTA Perkin Elmer, USA analyzer using $\mathrm{Al}_{2} \mathrm{O}_{3}$ as reference. The sample was heated at a rate of $10{ }^{\circ} \mathrm{C} / \mathrm{min}$ in the range of $40-300{ }^{\circ} \mathrm{C}$.

\subsection{HPLC Analysis}

The concentration of AZT was measured in its cocrystals using a previously reported method [67]. The analysis was performed using Agilent-1260 instrument with the PDA (Shimadzu, Japan). The method was performed on reversed phase column ZORABEX Eclipse Plus C18 $(4.6 \times 250 \mathrm{~mm}, 5 \mu \mathrm{m})$. Methanol:phosphate buffer $(9: 1, v / v)$ was used as a mobile phase at a flow rate of $1.2 \mathrm{~mL} / \mathrm{min}$ with a PDA detector, $210 \mathrm{~nm}$. The temperature was adjusted to $40^{\circ} \mathrm{C}$ with an injection volume of $50 \mu \mathrm{L}$. The AZT DH $(1 \mathrm{mg} / \mathrm{mL})$ and an equivalent concentration of the respective cocrystal solution were prepared in the mobile phase. Both solutions were run, and the concentration of AZT in cocrystals was measured.

\subsection{In Vitro Powder Dissolution}

Dissolution tests of AZT DH in pure state and cocrystal were carried out using USP apparatus type-2 (paddle method). An ADV 06 was operated under the sink condition. Cocrystals and drug were converted to fine powder and sieved through 100-mesh sieves to reduce effect of size on dissolution rate. An exact amount, $100 \mathrm{mg}$ of the drug and an equivalent amount of the cocrystal was taken and added to the vessels of dissolution apparatus containing $900 \mathrm{~mL}$ phosphate buffer $\mathrm{pH}$ 6.8. The rotation speed of the paddle was adjusted to $75 \mathrm{rpm}$ at $37{ }^{\circ} \mathrm{C}$ and aliquots of $5 \mathrm{~mL}$, withdrawn at predetermine time interval up to $60 \mathrm{~min}$. After withdrawing aliquots, the same volume of dissolution medium was added to vessel. The same procedure was followed for acetate buffer $(\mathrm{pH} 4.5)$ and 
$0.1 \mathrm{mM} \mathrm{HCl}$ dissolution medium. The samples were filtered, and percent drug releases were analyzed by HPLC. All the dissolution tests were performed in triplicate, and mean values were noted.

\subsection{Saturation Solubility Studies}

To study saturation solubility of AZT DH and cocrystal, saturation solubility test was carried out. Excess amount of the drug and the cocrystal were added to $100 \mathrm{~mL}$ of distilled water and a phosphate buffer solution ( $\mathrm{pH}$ 6.8). Samples were stirred at $100 \mathrm{rpm}$ at $37^{\circ} \mathrm{C}$ for $24 \mathrm{~h}$, filtered, suitably diluted and analyzed by HPLC. The saturation solubility determination experiments were performed in triplicate and respective mean values were noted.

\subsection{In Vitro Antibacterial Study}

Petri dishes and an agar solution were sterilized in autoclave. A known volume of $20 \mathrm{~mL}$ agar solution under sterile conditions was added to each petri dish and incubated for $24 \mathrm{~h}$. The plates with no contamination were selected for further study. The bacterial strains (E. coli; MTCC 1687, S. typhi; MTCC 734, K. pneumonia; MTCC 1030) were inoculated to plates with the help of sterile swabs. The drug and equivalent amount of cocrystals $(1000 \mu \mathrm{g} / \mathrm{mL})$ solutions were separately prepared and further diluted to different concentrations $(500,250$ and $125 \mu \mathrm{g} / \mathrm{mL})$. From each solution $5 \mu \mathrm{L}$ were added to $6 \mathrm{~mm}$ filter paper discs. After ten minutes of drying, drug loaded $(5,2.5,1.25,0.62 \mu \mathrm{g})$ filter paper discs were placed on agar plates surface using sterile forceps. The plates were incubated $\left(37^{\circ} \mathrm{C}\right)$ for $24 \mathrm{~h}$ and diameters indicating the zone of inhibition were manually noted. The antibacterial activity was performed in triplicate and mean zone of inhibitions were determined.

The minimal inhibitory concentration (MIC) of the prepared cocrystal and pure AZT were also determined against E. coli, S. typhi and K. pneumonia using the broth dilution method. Two-fold serial dilutions of AZT DH and cocrystal were made in sterile nutrient broth to give concentrations ranging from $2-256 \mu \mathrm{g} / \mathrm{mL}$. Ten sterile tubes were placed on a rack, each labeled 1 through 8 , along with a positive control and negative control. About $1 \mathrm{~mL}$ of different concentrations of the drug were added in to separate test tubes and inoculated with $1 \mathrm{~mL}$ bacterial suspensions $\left(10^{6} \mathrm{CFU} / \mathrm{mL}\right)$ of selected strain. The inoculated tubes were incubated at $37^{\circ} \mathrm{C}$ for $24 \mathrm{~h}$ after which they were inspected for turbidity. A positive control (growth) was formed by culture broth with microorganisms while the negative control (sterility) consisted of broth with no microorganisms.

The micrometric analysis details are elaborated in supplementary file with summarized results in Table S2, giving useful information about resultant products.

\section{Conclusions and Future Work}

Cocrystallization for designing and synthesis of DDCs is of pivotal and immense importance in pharmaceutical industry to manipulate physicochemical properties of APIs. In this work, AZT-PCM cocrystals were prepared and successfully isolated using solvent evaporation method. The characterization techniques such as FTIR, Raman, PXRD, DSC, TG and HPLC were successfully employed for cocrystal confirmation. Cocrystal exhibited better dissolution, solubility and antimicrobial performance than parental AZT DH drug. However, the effectiveness of the synthesized cocrystal needs in vivo confirmation. Though cocrystals were preliminary confirmed by different characterization techniques, for detailed structural characterization and discussion on exact interaction and related information, single XRD analysis is warranted. The field of drug-drug cocrystallization has bright chances to emerge in future studies. The efficiency was improved against the bacterial strains. The heterosynthons is efficient against K. pneumonia followed by E. coli and S. typhi.

Supplementary Materials: The following are available online at https://www.mdpi.com/article/10 .3390 / antibiotics10080939/s1, Supporting file contains binary phase diagram (Figure S1), melting points of starting material (Table S1) and their micrometric studies (Table S2). These materials can be found in online version of the manuscript [72-75]. 
Author Contributions: N.U.I.; Performed experiments, E.K.; Project administration writing of paper original and revised draft, M.N.U.; Supervision, A.S.; characterization of samples, M.Z.; Supervision and writing of paper original and revised draft, R.U.; Characterization of samples, help in write up, revisions and resources, and A.B.; Characterization of samples help in write up, revisions and resources. All authors have read and agreed to the published version of the manuscript.

Funding: This research was funded by King Saud University Research Supporting Project Number: RSP-2021/346.

Institutional Review Board Statement: Not applicable.

Informed Consent Statement: Not applicable.

Data Availability Statement: All the data associated with this paper has been presented in this manuscript. Not data in any repository is available to be linked here.

Acknowledgments: Authors wish to thanks Research Supporting Project Number: RSP-2021/346 King Saud University Riyadh Saudi Arabia for their financial support.

Conflicts of Interest: The authors declare no conflict of interest.

\section{References}

1. Thipparaboina, R.; Kumar, D.; Chavan, R.; Shastri, N.R. Multidrug Co-Crystals: Towards the Development of Effective Therapeutic Hybrids. Drug Discov. Today 2016, 21, 481-490. [CrossRef]

2. Lee, H.-G.; Zhang, G.G.; Flanagan, D. Cocrystal Intrinsic Dissolution Behavior Using a Rotating Disk. J. Pharm. Sci. 2011, 100, 1736-1744. [CrossRef]

3. Collenburg, L.; Beyersdorf, N.; Wiese, T.; Arenz, C.; Saied, E.M.; Becker-Flegler, K.A.; Schneider-Schaulies, S.; Avota, E. The Activity of the Neutral Sphingomyelinase Is Important in T Cell Recruitment and Directional Migration. Front. Immunol. 2017, 8. [CrossRef]

4. Bhatt, P.M.; Azim, Y.; Thakur, T.; Desiraju, G.R. Co-Crystals of the Anti-HIV Drugs Lamivudine and Zidovudine. Cryst. Growth Des. 2009, 9, 951-957. [CrossRef]

5. Bin-Jumah, M.; Abdel-Fattah, A.-F.M.; Saied, E.M.; El-Seedi, H.R.; Abdel-Daim, M.M. Acrylamide-Induced Peripheral Neuropathy: Manifestations, Mechanisms, and Potential Treatment Modalities. Environ. Sci. Pollut. Res. 2021, 28, 13031-13046. [CrossRef] [PubMed]

6. Grobelny, P.; Mukherjee, A.; Desiraju, G.R. Drug-Drug Co-Crystals: Temperature-Dependent Proton Mobility in the Molecular Complex of Isoniazid with 4-Aminosalicylic Acid. CrystEngComm 2011, 13, 4358-4364. [CrossRef]

7. Banhart, S.; Saied, E.M.; Martini, A.; Koch, S.; Aeberhard, L.; Madela, K.; Arenz, C.; Heuer, D. Improved Plaque Assay Identifies a Novel Anti-Chlamydia Ceramide Derivative with Altered Intracellular Localization. Antimicrob. Agents Chemother. 2014, 58, 5537-5546. [CrossRef] [PubMed]

8. Shinozaki, T.; Ono, M.; Higashi, K.; Moribe, K. A Novel Drug-Drug Cocrystal of Levofloxacin and Metacetamol: Reduced Hygroscopicity and Improved Photostability of Levofloxacin. J. Pharm. Sci. 2019, 108, 2383-2390. [CrossRef] [PubMed]

9. Thakuria, R.; Sarma, B. Drug-Drug and Drug-Nutraceutical Cocrystal/Salt as Alternative Medicine for Combination Therapy: A Crystal Engineering Approach. Crystals 2018, 8, 101. [CrossRef]

10. Montejo-Bernardo, J.M.; Garcia-Granda, S.; Bayod-Jasanada, M.S.; Llavona-Díaz, L.; Llorente, I. On the Solid State Conformation of Azithromycin Monohydrate and Dihydrate Pseudopolymorphs. Z. Für Krist. Cryst. Mater. 2005, 220, 66-73. [CrossRef]

11. Neglur, R.; Hosten, E.; Aucamp, M.; Liebenberg, W.; Grooff, D. Water and the Relationship to the Crystal Structure Stability of Azithromycin. J. Therm. Anal. Calorim. 2018, 132, 373-384. [CrossRef]

12. Montejo-Bernardo, J.M.; García-Granda, S. New Solvated form of the Antibiotic Azithromycin. Clues about the Role of the Water Retained inside the Crystal. Z. Für Krist. 2007, 222, 492-497. [CrossRef]

13. Montejo-Bernardo, J.M.; García-Grande, S.; Bayod-Jasanada, M.S.; Lavona-Díaz, L.; Llorente, I. X-ray Study of the Pseudopolymorphism of the Azithromycin Monohydrate. Z. Für Krist. Cryst. Mater. 2003, 218, 703-707. [CrossRef]

14. Blanco, M.; Valdés, D.; Llorente, I.; Bayod, M. Application of NIR Spectroscopy in Polymorphic Analysis: Study of PseudoPolymorphs Stability. J. Pharm. Sci. 2005, 94, 1336-1342. [CrossRef] [PubMed]

15. Idkaidek, N.M.; Najib, N.M.; Salem, I.; Jilani, J. Physiologically-Based IVIVC of Azithromycin. Am. J. Pharmacol. Sci. 2014, 2, 100-102. [CrossRef]

16. Pacifico, L.; Chiesa, C. Azithromycin in Children: A Critical Review of the Evidence. Curr. Ther. Res. 2002, 63, 54-76. [CrossRef]

17. Saied, E.M.; Banhart, S.; Bürkle, S.E.; Heuer, D.; Arenz, C. A Series of Ceramide Analogs Modified at the 1-Position with Potent Activity against the Intracellular Growth of Chlamydia Trachomatis. Future Med. Chem. 2015, 7, 1971-1980. [CrossRef]

18. Lode, H.; Borner, K.; Koeppe, P.; Schaberg, T.; Lode, H.; Borner, K.; Koeppe, P.; Schaberg, T. Azithromycin-Review of Key Chemical, Pharmacokinetic and Microbiological Features. J. Antimicrob. Chemother. 1996, 37, 1-8. [CrossRef] 
19. Shaikh, K.; Patil, S.; Devkhile, A. Development and Validation of a Reversed-Phase HPLC Method for Simultaneous Estimation of Ambroxol Hydrochloride and Azithromycin in Tablet Dosage Form. J. Pharm. Biomed. Anal. 2008, 48, 1481-1484. [CrossRef] [PubMed]

20. Breier, A.; Garcia, C.; Oppe, T.; Steppe, M.; Schapoval, E. Microbiological Assay for Azithromycin in Pharmaceutical Formulations. J. Pharm. Biomed. Anal. 2002, 29, 957-961. [CrossRef]

21. Arora, S.C.; Sharma, P.K.; Irchhaiya, R.; Khatkar, A.; Singh, N.; Gagoria, J. Development, Characterization and Solubility Study of Solid Dispersions of Azithromycin Dihydrate by Solvent Evaporation Method. J. Adv. Pharm. Technol. Res. 2010, 1, 221-228. [CrossRef]

22. Tung, N.-T.; Tran, L.N.; Nguyen, T.-L.; Hoang, T.; Trinh, T.-D.; Nguyen, T.-N. Formulation and Biopharmaceutical Evaluation of Bitter Taste Masking Microparticles Containing Azithromycin Loaded in Dispersible Tablets. Eur. J. Pharm. Biopharm. 2018, 126, 187-200. [CrossRef]

23. Tong, L.; Eichhorn, P.; Pérez, S.; Wang, Y.; Barceló, D. Photodegradation of Azithromycin in Various Aqueous Systems under Simulated and Natural Solar Radiation: Kinetics and Identification of Photoproducts. Chemosphere 2011, 83, 340-348. [CrossRef] [PubMed]

24. Samak, D.H.; El-Sayed, Y.S.; Shaheen, H.M.; El-Far, A.H.; Abd El-Hack, M.E.; Noreldin, A.E.; El-Naggar, K.; Abdelnour, S.A.; Saied, E.M.; El-Seedi, H.R.; et al. Developmental Toxicity of Carbon Nanoparticles during Embryogenesis in Chicken. Environ. Sci. Pollut. Res. 2020, 27, 19058-19072. [CrossRef] [PubMed]

25. Khan, F.A.; Zahoor, M.; Islam, N.U.; Hameed, R. Synthesis of Cefixime and Azithromycin Nanoparticles: An Attempt to Enhance Their Antimicrobial Activity and Dissolution Rate. J. Nanomater. 2016, 2016, 1-9. [CrossRef]

26. Hou, C.-D.; Wang, J.-X.; Le, Y.; Zou, H.-K.; Zhao, H. Preparation of Azithromycin Nanosuspensions by Reactive Precipitation Method. Drug Dev. Ind. Pharm. 2011, 38, 848-854. [CrossRef] [PubMed]

27. Nirmala, M.J.; Viswanadha, S.; Mukherjee, A.; Chandrasekaran, N. Improved Physico-Chemical Aspects of Azithromycin through Novel Microemulsion System. Int. J. Pharm. Pharm. Sci. 2013, 5, 700-702.

28. Adeli, E. Preparation and Evaluation of Azithromycin Binary Solid Dispersions Using Various Polyethylene Glycols for the Improvement of the Drug Solubility and Dissolution Rate. Braz. J. Pharm. Sci. 2016, 52, 3602-3613. [CrossRef]

29. Mangal, S.; Xu, R.; Park, H.; Zemlyanov, D.; Shetty, N.; Lin, Y.-W.; Morton, D.; Chan, H.-K.; Li, J.; Zhou, Q.T. Understanding the Impacts of Surface Compositions on the In-Vitro Dissolution and Aerosolization of Co-Spray-Dried Composite Powder Formulations for Inhalation. Pharm. Res. 2018, 36, 6. [CrossRef]

30. Gaber, A.; Alsanie, W.F.; Kumar, D.N.; Refat, M.S.; Saied, E.M. Novel Papaverine Metal Complexes with Potential Anticancer Activities. Molecules 2020, 25, 5447. [CrossRef]

31. Hu, L.; Pan, J.; Liu, C.; Xu, H.; Luo, L. Preparation, Characterization and Taste-Masking Properties of Microspheres Containing Azithromycin. J. Pharm. Pharmacol. 2009, 61, 1631-1635. [CrossRef] [PubMed]

32. Amin, F.; Khan, S.; Shah, S.M.H.; Rahim, H.; Hussain, Z.; Sohail, M.; Ullah, R.; Alsaid, M.S.; Shahat, A.A. A New Strategy for Taste Masking of Azithromycin Antibiotic: Development, Characterization, and Evaluation of Azithromycin Titanium Nanohybrid for Masking of Bitter Taste Using Physisorption and Panel Testing Studies. Drug Des. Dev. Ther. 2018, 12, 3855-3866. [CrossRef]

33. Nichols, G.; Frampton, C.S. Physicochemical Characterization of the Orthorhombic Polymorph of Paracetamol Crystallized from Solution. J. Pharm. Sci. 1998, 87, 684-693. [CrossRef] [PubMed]

34. Perrin, M.-A.; Neumann, M.A.; Elmaleh, H.; Zaske, L. Crystal Structure Determination of the Elusive Paracetamol Form III. Chem. Commun. 2009, 22, 3181-3183. [CrossRef] [PubMed]

35. Meloun, M.; Syrový, T.; Vrána, A. The Thermodynamic Dissociation Constants of Losartan, Paracetamol, Phenylephrine and Quinine by the Regression Analysis of Spectrophotometric Data. Anal. Chim. Acta 2005, 533, 97-110. [CrossRef]

36. Maeno, Y.; Fukami, T.; Kawahata, M.; Yamaguchi, K.; Tagami, T.; Ozeki, T.; Suzuki, T.; Tomono, K. Novel Pharmaceutical Cocrystal Consisting of Paracetamol and Trimethylglycine, a New Promising Cocrystal Former. Int. J. Pharm. 2014, 473, 179-186. [CrossRef]

37. Leyk, E.; Wesolowski, M. Interactions between Paracetamol and Hypromellose in the Solid State. Front. Pharmacol. 2019, 10, 14. [CrossRef] [PubMed]

38. Latif, S.; Abbas, N.; Hussain, A.; Arshad, M.S.; Bukhari, N.I.; Afzal, H.; Riffat, S.; Ahmad, Z. Development of Paracetamol-caffeine Co-Crystals to Improve Compressional, Formulation and In Vivo Performance. Drug Dev. Ind. Pharm. 2018, 44, 1099-1108. [CrossRef]

39. Bolla, G.; Nangia, A. Pharmaceutical Cocrystals: Walking the Talk. Chem. Commun. 2016, 52, 8342-8360. [CrossRef] [PubMed]

40. Aakeröy, C. Is There Any Point in Making Co-Crystals? Acta Crystallogr. Sect. B Struct. Sci. Cryst. Eng. Mater. 2015, 71, 387-391.

41. Gaber, A.; Refat, M.S.; Belal, A.A.M.; El-Deen, I.M.; Hassan, N.; Zakaria, R.; Alhomrani, M.; Alamri, A.S.; Alsanie, W.F.; Saied, E.M. New Mononuclear and Binuclear Cu(II), Co(II), Ni(II), and Zn(II) Thiosemicarbazone Complexes with Potential Biological Activity: Antimicrobial and Molecular Docking Study. Molecules 2021, 26, 2288. [CrossRef] [PubMed]

42. Capucci, D.; Balestri, D.; Mazzeo, P.; Pelagatti, P.; Rubini, K.; Bacchi, A. Liquid Nicotine Tamed in Solid Forms by Cocrystallization. Cryst. Growth Des. 2017, 17, 4958-4964. [CrossRef]

43. Lone, M.A.; Hülsmeier, A.J.; Saied, E.M.; Karsai, G.; Arenz, C.; von Eckardstein, A.; Hornemann, T. Subunit Composition of the Mammalian Serine-Palmitoyltransferase Defines the Spectrum of Straight and Methyl-Branched Long-Chain Bases. Proc. Natl. Acad. Sci. USA 2020, 117, 15591-15598. [CrossRef] [PubMed] 
44. Karimi-Jafari, M.; Padrela, L.; Walker, G.; Croker, D. Creating Cocrystals: A Review of Pharmaceutical Cocrystal Preparation Routes and Applications. Cryst. Growth Des. 2018, 18, 6370-6387. [CrossRef]

45. Refat, M.S.; Ibrahim, H.K.; Sowellim, S.Z.A.; Soliman, M.H.; Saeed, E.M. Spectroscopic and Thermal Studies of Mn(II), Fe(III), $\mathrm{Cr}(\mathrm{III})$ and $\mathrm{Zn}$ (II) Complexes Derived from the Ligand Resulted by the Reaction Between 4-Acetyl Pyridine and Thiosemicarbazide. J. Inorg. Organomet. Polym. 2009, 19, 521. [CrossRef]

46. Brittain, H.G. Vibrational Spectroscopic Studies of Cocrystals and Salts. 2. The Benzylamine-Benzoic Acid System. Cryst. Growth Des. 2009, 9, 3497-3503. [CrossRef]

47. Trivedi, M.K.; Patil, S.; Shettigar, H.; Bairwa, K.; Jana, S. Effect of Biofield Treatment on Spectral Properties of Paracetamol and Piroxicam. Chem. Sci. J. 2015, 6, 98-103. [CrossRef]

48. Srivastava, K.; Shimpi, M.R.; Srivastava, A.; Tandon, P.; Sinha, K.; Velaga, S.P. Vibrational Analysis and Chemical Activity of Paracetamol-Oxalic acid Cocrystal Based on Monomer and Dimer Calculations: DFT and AIM Approach. RSC Adv. 2016, 6, 10024-10037. [CrossRef]

49. Walsh, D.; Serrano, D.R.; Worku, Z.A.; Madi, A.; O'Connell, P.; Twamley, B.; Healy, A.M. Engineering of Pharmaceutical Cocrystals in an Excipient Matrix: Spray Drying Versus Hot Melt Extrusion. Int. J. Pharm. 2018, 551, 241-256. [CrossRef] [PubMed]

50. Golovnev, N.N.; Molokeev, M.S.; Lesnikov, M.K.; Atuchin, V.V. Two Salts and the Salt Cocrystal of Ciprofloxacin with Thiobarbituric and Barbituric Acids: The Structure and Properties. J. Phys. Org. Chem. 2018, 31, e3773. [CrossRef]

51. Wang, C.; Tong, Q.; Hou, X.; Hu, S.; Fang, J.; Sun, C.C. Enhancing Bioavailability of Dihydromyricetin through Inhibiting Precipitation of Soluble Cocrystals by a Crystallization Inhibitor. Cryst. Growth Des. 2016, 16, 5030-5039. [CrossRef]

52. Nicolov, M.; Ghiulai, R.M.; Voicu, M.; Mioc, M.; Duse, A.O.; Roman, R.; Ambrus, R.; Zupko, I.; Moaca, E.A.; Coricovac, D.E.; et al. Cocrystal Formation of Betulinic Acid and Ascorbic Acid: Synthesis, Physico-Chemical Assessment, Antioxidant, and Antiproliferative Activity. Front. Chem. 2019, 7, 92-102. [CrossRef] [PubMed]

53. Mangal, S.; Nie, H.; Xu, R.; Guo, R.; Cavallaro, A.; Zemlyanov, D.; Zhou, Q. (Tony) Physico-Chemical Properties, Aerosolization and Dissolution of Co-Spray Dried Azithromycin Particles with L-Leucine for Inhalation. Pharm. Res. 2018, 35, 1-15. [CrossRef]

54. Elbagerma, M.A.; Edwards, H.G.M.; Munshi, T.; Scowen, I.J. Identification of a New Cocrystal of Citric Acid and Paracetamol of Pharmaceutical Relevance. CrystEngComm 2010, 13, 1877-1884. [CrossRef]

55. Sathisaran, I.; Dalvi, S.V. Cocrystallization of Carbamazepine with Amides: Cocrystal and Eutectic Phases with Improved Dissolution. J. Mol. Struct. 2019, 1193, 398-415. [CrossRef]

56. de Almeida, A.C.; Ferreira, P.O.; Torquetti, C.; Ekawa, B.; Carvalho, A.C.S.; dos Santos, E.C.; Caires, F.J. Mechanochemical Synthesis, Characterization and Thermal Study of New Cocrystals of Ciprofloxacin with Pyrazinoic acid and p-Aminobenzoic Acid. J. Therm. Anal. Calorim. 2020, 140, 2293-2303. [CrossRef]

57. Wu, S.; Shen, H.; Li, K.; Yu, B.; Xu, S.; Chen, M.; Gong, J.; Hou, B.H. Agglomeration Mechanism of Azithromycin Dihydrate in Acetone-Water Mixtures and Optimization of the Powder Properties. Ind. Eng. Chem. Res. 2016, 55, 4905-4910. [CrossRef]

58. Martinez, J.; Domínguez-Chávez, J.G.; Rivera-Islas, J.; Herrera-Ruiz, D.; Höpfl, H.; Morales-Rojas, H.; Senosiain, J.P. A Twist in Cocrystals of Salts: Changes in Packing and Chloride Coordination Lead to Opposite Trends in the Biopharmaceutical Performance of Fluoroquinolone Hydrochloride Cocrystals. Cryst. Growth Des. 2014, 14, 3078-3095. [CrossRef]

59. Liu, M.; Hong, C.; Yao, Y.; Shen, H.; Ji, G.; Li, G.; Xie, Y. Development of a Pharmaceutical Cocrystal with Solution Crystallization Technology: Preparation, Characterization, and Evaluation of Myricetin-Proline Cocrystals. Eur. J. Pharm. Biopharm. 2016, 107, 151-159. [CrossRef]

60. Kauss, T.; Gaubert, A.; Boyer, C.; Ba, B.B.; Manse, M.; Massip, S.; Léger, J.-M.; Fawaz, F.; Lembege, M.; Boiron, J.-M.; et al. Pharmaceutical Development and Optimization of Azithromycin Suppository for Paediatric Use. Int. J. Pharm. 2013, 441, 218-226. [CrossRef]

61. Maswadeh, H. Incompatibility of Paracetamol with Pediatric Suspensions Containing Amoxicillin, Azithromycin and Cefuroxime Axetil. Pharmacol. Pharm. 2017, 8, 355-368. [CrossRef]

62. Schultheiss, N.; Newman, A. Pharmaceutical Cocrystals and Their Physicochemical Properties. Cryst. Growth Des. 2009, 9, 2950-2967. [CrossRef]

63. Bandari, S.; Dronam, V.R.; Eedara, B.B. Development and Preliminary Characterization of Levofloxacin Pharmaceutical Cocrystals for Dissolution Rate Enhancement. J. Pharm. Investig. 2017, 47, 583-591. [CrossRef]

64. Sathisaran, I.; Dalvi, S.V. Engineering Cocrystals of Poorly Water-Soluble Drugs to Enhance Dissolution in Aqueous Medium. Pharmaceutics 2018, 10, 108. [CrossRef] [PubMed]

65. Timoumi, S.; Mangin, D.; Peczalski, R.; Zagrouba, F.; Andrieu, J. Stability and Thermophysical Properties of Azithromycin Dihydrate. Arab. J. Chem. 2014, 7, 189-195. [CrossRef]

66. Hiendrawan, S.; Veriansyah, B.; Widjojokusumo, E.; Soewandhi, S.N.; Wikarsa, S.; Tjandrawinata, R.R. Simultaneous Cocrystallization and Micronization of Paracetamol-Dipicolinic Acid Cocrystal by Supercritical Antisolvent (SAS). Int. J. Pharm. Pharm. Sci. 2016, 8, 89-98.

67. Renkoğlu, P.; Çelebier, M.; Arıca-Yegin, B. HPLC Determination of Olanzapine and Carbamazepine in Their Nicotinamide Cocrystals and Investigation of the Dissolution Profiles of Cocrystal Tablet Formulations. Pharm. Dev. Technol. 2013, 20, 380-384. [CrossRef] 
68. Sharar, M.; Saied, E.M.; Rodriguez, M.C.; Arenz, C.; Montes-Bayón, M.; Linscheid, M.W. Elemental Labelling and Mass Spectrometry for the Specific Detection of Sulfenic Acid Groups in Model Peptides: A Proof of Concept. Anal. Bioanal. Chem. 2017, 409, 2015-2027. [CrossRef]

69. Rajbhar, P.; Sahu, A.K.; Gautam, S.S.; Prasad, R.K.; Singh, V.; Nair, S.K. Formulation and Evaluation of Clarithromycin CoCrystals Tablets Dosage Forms to Enhance the Bioavailability. Pharma Innov. 2016, 5, 5-13.

70. Mesallati, H.; Umerska, A.; Paluch, K.J.; Tajber, L. Amorphous Polymeric Drug Salts as Ionic Solid Dispersion Forms of Ciprofloxacin. Mol. Pharm. 2017, 14, 2209-2223. [CrossRef] [PubMed]

71. Hussein, A.; Al-Janabi, A.A.H.S. In Vitro Antibacterial Activity of Ibuprofen and Acetaminophen. J. Glob. Infect. Dis. 2010, 2, 105-108. [CrossRef] [PubMed]

72. Nugrahani, I.; Utami, D.; Nugraha, Y.P.; Uekusa, H.; Hasianna, R.; Darusman, A.A. Cocrystal construction between the ethyl ester with parent drug of diclofenac: Structural, stability, and anti-inflammatory study. Heliyon 2019, 5, e02946. [CrossRef] [PubMed]

73. Evora, A.O.; Castro, R.A.; Maria, T.M.; Silva, M.R.; Canotilho, J.; Eusébio, M.E.S. Lamotrigine: Design and synthesis of new multicomponent solid forms. Eur. J. Pharm. Sci. 2019, 129, 148-162. [CrossRef]

74. Yamashita, H.; Hirakura, Y.; Yuda, M.; Teramura, T.; Terada, K. Detection of cocrystal formation based on binary phase diagrams using thermal analysis. Pharm. Res. 2013, 30, 70-80. [CrossRef]

75. Nugrahani, I.; Tjengal, B.; Gusdinar, T.; Horikawa, A.; Uekusa, H. A Comprehensive Study of a New 1.75 Hydrate of Ciprofloxacin Salicylate: SCXRD Structure Determination, Solid Characterization, Water Stability, Solubility, and Dissolution Study. Crystals 2020, 10, 349. [CrossRef] 